\title{
Synthesis and Structure of the Perovskite-Type Phase $\mathrm{Ba}_{4} \mathrm{CuYW}_{2} \mathrm{O}_{12}$
}

\author{
Ingrid Bryntse
}

Department of Inorganic Chemistry, Arrhenius Laboratory, Stockholm University, S-106 91 Stockholm, Sweden

Bryntse, I., 1990. Synthesis and Structure of the Perovskite-Type Phase $\mathrm{Ba}_{4} \mathrm{CuYW}_{2} \mathrm{O}_{12}$ - Acta Chem. Scand. 44: 855-856.

Since the discovery of high- $T_{\mathrm{c}}$ superconducting phases in the $\mathrm{BaO}-\mathrm{CuO}-\mathrm{Y}_{2} \mathrm{O}_{3}$ system, ${ }^{1}$ substitutions in this system have been of interest. A substitution of tungsten for copper has recently been discussed. ${ }^{2}$

We present here a cubic perovskite-type phase of the formula $\mathrm{Ba}_{4} \mathrm{CuYW}_{2} \mathrm{O}_{12}$, with a cell parameter close to that reported for a supposedly superconducting phase, and a volume eight times the primitive perovskite unit.

Phase analysis. The starting chemicals, $\mathrm{BaCO}_{3}$ (Merck, p.a.), $\mathrm{CuO}$ (Schering, p.a.), $\mathrm{Y}_{2} \mathrm{O}_{3}$ (Starck, finest) and $\mathrm{WO}_{3}$ (Riedel de Haën, puriss), were ground together and pelletized. The pellets were placed in an alumina crucible, heated to $1000^{\circ} \mathrm{C}$ for about $24 \mathrm{~h}$ and cooled outside the furnace. The products were brown powders, and no reaction with the crucible could be noticed.

The X-ray powder patterns were taken in a GuinierHägg focussing camera with $\mathrm{Si}$ as internal standard $\left(a_{\mathrm{Si}}=5.43088 \AA\right.$ at $\left.25^{\circ} \mathrm{C}\right)$, and the films were automatically scanned. ${ }^{3}$ Starting compositions corresponding to $\mathrm{Ba}_{2} \mathrm{Cu}_{2} \mathrm{YWO}_{8.5}$ gave clearly polyphasic samples.

However, when the composition was close to the ratio $\mathrm{Ba}: \mathrm{Cu}: \mathrm{Y}: \mathrm{W}=4: 1: 1: 2$ the Guinier film showed a cubic pattern with only one very weak extra line. The pattern was indexed on the basis of a face-centred cell with $a=$ 8.3065 (6) A (Table 1).

Part of this sample was ground in butanol and placed on a holey carbon film on top of a pure nickel grid. The crystal fragments were analyzed in a JEOL 2000FX transmission electron microscope equipped with a standard EDS detector at the $70^{\circ}$ take-off position (LINK QX200). Selectedarea electron diffraction along the $\langle 100\rangle$ zone axis was compatible with a cubic $F$-centred cell with $a \approx 8.3 \AA$. Reflections $h k 0$ with $h+k=4 n$ were markedly stronger than the rest. The EDS analyses of a large number of thin fragments indicated that the weighted-in stoichiometry was preserved, and no impurities could be detected. All crystals analyzed gave roughly the same metal ratio.

A sample of the unreacted powder $(26.73 \mathrm{mg})$ was heated in air in a Perkin Elmer thermogravimetry appara- tus. The heating rate was $2{ }^{\circ} \mathrm{C} \mathrm{min}^{-1}$ in the temperature range $500-1000^{\circ} \mathrm{C}$. The measured loss of weight in this experiment was $12.9 \%$. If the total reaction is assumed to be given by reaction (1), the loss of weight should be $12.7 \%$. The small difference between this calculated value and the one measured could be explained by moisture or a slight volatilazation of $\mathrm{WO}_{3}$.

$$
\begin{aligned}
& 8 \mathrm{BaCO}_{3}+2 \mathrm{CuO}+\mathrm{Y}_{2} \mathrm{O}_{3}+4 \mathrm{WO}_{3} \rightarrow \\
& 2 \mathrm{Ba}_{4} \mathrm{CuYW}_{2} \mathrm{O}_{12}+8 \mathrm{CO}_{2}+\frac{1}{2} \mathrm{O}_{2}
\end{aligned}
$$

Structure refinement. Since the composition was found to be close to that of an ideal perovskite, $\mathrm{ABO}_{3}$, we assumed barium to be in the $A$-position and the smaller atoms cop-

Table 1. Observed and calculated $d$-values for the Guinier-Hägg $\mathrm{X}$-ray powder diffraction pattern of $\mathrm{Ba}_{4} \mathrm{CuYW}_{2} \mathrm{O}_{12}$. The observed and calculated intensities are from a Rietveld refinement based on data obtained from a STOE powder diffractometer. $\lambda=$

\begin{tabular}{|c|c|c|c|c|c|c|}
\hline$h$ & $k$ & 1 & $\left.d_{\mathrm{obs}}\right\rfloor \AA$ & $d_{\text {cald }} d \AA$ & $I_{\text {obs }}$ & $I_{\text {calc }}$ \\
\hline 1 & 1 & 1 & 4.7976 & 4.7957 & 12.5 & 12.0 \\
\hline 2 & 0 & 0 & 4.1518 & 4.1532 & 0.9 & 0.7 \\
\hline 2 & 2 & 0 & 2.9360 & 2.9368 & 100.0 & 100.0 \\
\hline 3 & 1 & 1 & 2.5038 & 2.5045 & 6.1 & 5.5 \\
\hline 2 & 2 & 2 & 2.3973 & 2.3979 & 2.5 & 2.2 \\
\hline 4 & 0 & 0 & 2.0768 & 2.0766 & 27.0 & 28.1 \\
\hline 3 & 3 & 1 & 1.9054 & 1.9056 & 1.8 & 2.0 \\
\hline 4 & 2 & 2 & 1.6958 & 1.6955 & 37.7 & 37.4 \\
\hline $\begin{array}{l}3 \\
5\end{array}$ & $\begin{array}{l}3 \\
1\end{array}$ & $\begin{array}{l}3 \\
1\end{array}$ & 1.5993 & 1.5986 & 2.6 & 2.6 \\
\hline 4 & 4 & 0 & 1.4688 & 1.4684 & 15.6 & 16.0 \\
\hline 5 & 3 & 1 & 1.4045 & 1.4040 & 1.6 & 2.5 \\
\hline 6 & 2 & 0 & 1.3137 & 1.3134 & 14.7 & 15.6 \\
\hline 5 & 3 & 3 & 1.2669 & 1.2667 & 0.9 & 0.8 \\
\hline 4 & 4 & 4 & 1.1989 & 1.1989 & 5.4 & 4.9 \\
\hline $\begin{array}{l}5 \\
7\end{array}$ & $\begin{array}{l}5 \\
1\end{array}$ & $\begin{array}{l}1 \\
1\end{array}$ & 1.1626 & 1.1631 & 1.9 & 1.4 \\
\hline 6 & 4 & 2 & 1.1099 & 1.1100 & 17.7 & 17.7 \\
\hline
\end{tabular}
$1.540598 \AA$. 
Table 2. Positional parameters of $\mathrm{Ba}_{4} \mathrm{CuYW}_{2} \mathrm{O}_{12}$ and individual isotropic temperature factors, with estimated standard deviations in parentheses.

\begin{tabular}{lrllll}
\hline Atom & Position & $x / a$ & $y / b$ & $z / c$ & $B / \AA^{2}$ \\
\hline$W$ & $4(a)$ & 0 & 0 & 0 & $1.0(2)$ \\
$\mathrm{Cu}, \mathrm{Y}$ & $4(b)$ & $1 / 2$ & $1 / 2$ & $1 / 2$ & $2.8(3)$ \\
$\mathrm{Ba}$ & $8(c)$ & $1 / 4$ & $1 / 4$ & $1 / 4$ & $0.4(1)$ \\
$\mathrm{O}$ & $24(e)$ & $0.232(3)$ & 0 & 0 & $1.7(4)$ \\
\hline
\end{tabular}

per, yttrium and tungsten in the $B$-positions. $F m 3 m$ is then a possible space group if $\mathrm{Cu}$ and $\mathrm{Y}$ are statistically distributed in $4 b$ and four W located in $4 a$ (Table 2).

$\mathrm{X}$-ray powder data for Rietveld refinement were collected on a STOE STADI/P powder diffractometer, using a rotating sample in a symmetric transmission mode. Step intensities in the $2 \theta$-range $10-120^{\circ}$ were used in the refinement (step length $\Delta 2 \theta=0.02^{\circ}$ ).

Full-profile Rietveld refinement of the structure was carried out with the program DBW3.2S. ${ }^{4}$ The following parameters were refined: one positional parameter, five isotropic temperature factors, one zero-point parameter, one scale factor and three half-width parameters. It was noticed that the maximum value for the half-widths was rather large, $0.65^{\circ}(2 \theta)$. The refinement was terminated when all shifts in the parameters were less than $10 \%$ of the corresponding standard deviations. The final $R$-values, $R_{\mathrm{p}}=$ $0.046, R_{\text {wp }}=0.060, R_{\mathrm{Bragg}}=0.048$ and $R_{\mathrm{F}}=0.068$, were obtained for the positional parameter and temperature factors in Table 2. Observed and calculated intensities are listed in Table 1. The bond lengths are $\mathrm{Cu}(\mathrm{Y})-6 \mathrm{O}=2.23(3)$ $\AA, \mathrm{W}-6 \mathrm{O}=1.93(3) \AA$ and $\mathrm{Ba}-12 \mathrm{O}=2.941(1) \AA$.
In separate refinement cycles the occupation factors were checked. However, no significant deviation from the assumed formula was seen.

This new phase in the $\mathrm{Ba}-\mathrm{Cu}-\mathrm{Y}-\mathrm{W}-\mathrm{O}$ system is a member of the perovskite family $\mathrm{Ba}_{2} M \mathrm{WO}_{6}(M=\mathrm{Mg}, \mathrm{Zn}, \mathrm{Ni}$, Ca) reported by Filipev $e t a l .{ }^{5}$ The refinement indicates that $\mathrm{Cu}$ and $\mathrm{Y}$ share the $M$-positions. It is probable that $\mathrm{Cu}$ (II) is reduced to $\mathrm{Cu}(\mathrm{I})$, as suggested by the brown colour of the phase and the thermogravimetry experiment. The relatively high temperature factors for $\mathrm{Cu}$ and $\mathrm{Y}$ indicate that the true positions of these atoms may deviate slightly from the average symmetrical sites. The sample was found to be a very poor electric conductor at room temperature.

Acknowledgements. The author acknowledges valuable discussions with Prof. L. Kihlborg and Dr. J. Grins. This study is part of a project that has received financial support from the Swedish Natural Science Research Council.

\section{References}

1. Wu, M. K., Ashburn, J. R., Torng, C. J., Hor, P. H., Meng, R. L., Gao, L., Huang, Z. J., Wang, Y. Q. and Chu, C. W. Phys. Rev. Lett. 58 (1987) 908.

2. Bokhimi, MRS Fall Meeting 1989, Boston, Mass. See also discussions in Superconductor Week 3 (No. 46) (1989) 3 and 4 (No. 3) (1990) 1, as well as High Tc Update 4 (Nos. 3-5) (1989) 1

3. Johansson, K. E., Palm, T. and Werner, P.-E. J. Phys. E 13 (1980) 1289.

4. Wiles, D. B., Sakthivel, A. and Young, R. A. Program DBW $3.2 S$ (1987).

5. Filipev, V. S., Shatalova, G. E. and Fesenko, E. G. Sov. Phys. Crystallogr. (Engl. Transl.) 19 (1974) 236.

Received March 28, 1990. 